EESTI NSV TEADUSTE AKADEEMIA TOIMETISED. XVI KOIDE

KEEMIA * GEOLOOGIA. 1967, Nr. 4

ИЗВЕСТИЯ АКАДЕМИИ НАУК ЭСТОНСКОЙ ССР. ТОМ ХV!

ХИМИЯ * ГЕОЛОГИЯ. 1957. № 4

S. RANG, T. PEHK, E. LIPPMAA, O. EISEN

\title{
CARBON-13 CHEMICAL SHIFTS OF NORMAL ALKYNES
}

3. RANG, T. PEHK, E. LIPPMAA, O. EISEN. SOSINIK-13 KEEMILISED NIHKED SIRGE AHELAGA ALKOUONIDES

С. РАНГ, Т. ПЕХК, Э. ЛИППМАА, О. ЭПЗЕН. ХИМИЧЕСКИЕ СДВИГИ УГЛЕРОДА-1З н-АЛКИНОВ

Carbon-13 spectra of a few simple acetylenes have been investigated by Lauterbur [ $\left.{ }^{1}\right]$, Friedel and Retcofsky [ $\left.{ }^{2}\right]$ and others $\left[{ }^{3,4}\right.$ ]. Only the chemical shifts of the sp-hybridized carbon atoms were measured and found to fall into a rather narrow range of 104 to $126 \mathrm{ppm}$ from $\mathrm{CS}_{2}$ $\left.{ }^{5,6}\right]$ that is usually free from other carbon-13 signals and can be used for the identification of triple bonds.

Very little is known about the chemical shifts of saturated carbon atoms in alkynes. Friedel and Retcofsky note that the methyl resonance in dimethylacetylene is found at higher field than the corresponding shift in both toluene and 2,3-pentadiene, but give no numerical data. The saturated methyl and methylene carbon atoms yield very complicated spectra of weak overlapping multiplets ([3], Fig. 9; [4], Fig. 1) where no exact determination of chemical shifts is possible. Nevertheless these shifts are important in structural analysis [ $\left.{ }^{17}\right]$ and allow to assess the importance of magnetic anisotropy of the triple bond for carbon chemical shifts. Although this bond anisotropy has been estimated as $-1.6 \cdot 10^{-6} \mathrm{~cm}^{3} /$ mole to $-34.2 \cdot 10^{-6} \mathrm{~cm}^{3} /$ mole [18] with the most probable values $\Delta \chi=-11.8 \cdot 10^{-6} \mathrm{~cm}^{3} /$ mole $[7]$ and $\Delta \chi=-16.5 \cdot 10^{-6} \mathrm{~cm}^{3} / \mathrm{mole}^{[8]}$, no exact data are available and the problem of anisotropy effects in carbon-13 spectroscopy is not at all clear [ $\left.{ }^{4}\right]$.

Spin decoupling with a strong perturbing rf field $\mathrm{H}_{2}$ acting on the hydrogen spins [9] is a powerful method for spectrum simplification, since every carbon atom is represented by a single sharp line with no splitting if

$$
|\gamma| H_{2} \gg 2 \pi|J| ; 2 \pi\left|10^{6} \Delta \delta\right|
$$

where $\Delta \delta$ is the range of the hydrogen chemical shifts and $J=J_{\left(\mathrm{C}^{13} \mathrm{H}\right)}$ are the corresponding coupling constants. Multiplet collapse is accompanied by a two- or threefold increase in peak value and an additional increase in line intensity (and the peak value) is possible as a result of the nuclear Overhauser effect. Using the symbols of Abragam $\left(\left[{ }^{10}\right]\right.$, p. 337) we have 


$$
\left\langle I_{z}>/ I_{0}=1+(\sigma / \varrho)\left(S_{0} / I_{0}\right)\right.
$$

where $\left\langle I_{z}\right\rangle$ is the steady state and $I_{0}$ the equilibrium magnetization of the carbon-13 nuclei. Since $\sigma / \varrho=1 / 2$ for dipole-dipole relaxation and $\mathrm{S}_{0} / I_{0}=\gamma_{\mathrm{H}} / \gamma_{\mathrm{C}} \cong 4$, an up to threefold increase in line intensity is possible. In benzene an increase of peak value up to 5.5 times has been achieved, but this is not always the case since other relaxation processes [ $\left.{ }^{19}\right]$ interfere, diminishing the $\sigma / \varrho$ ratio. The effect does not depend on scalar spin-spin coupling and strong enhancement is achieved for unsubstituted sp-carbons in 2-octyne (Fig. 1) if the methyl and

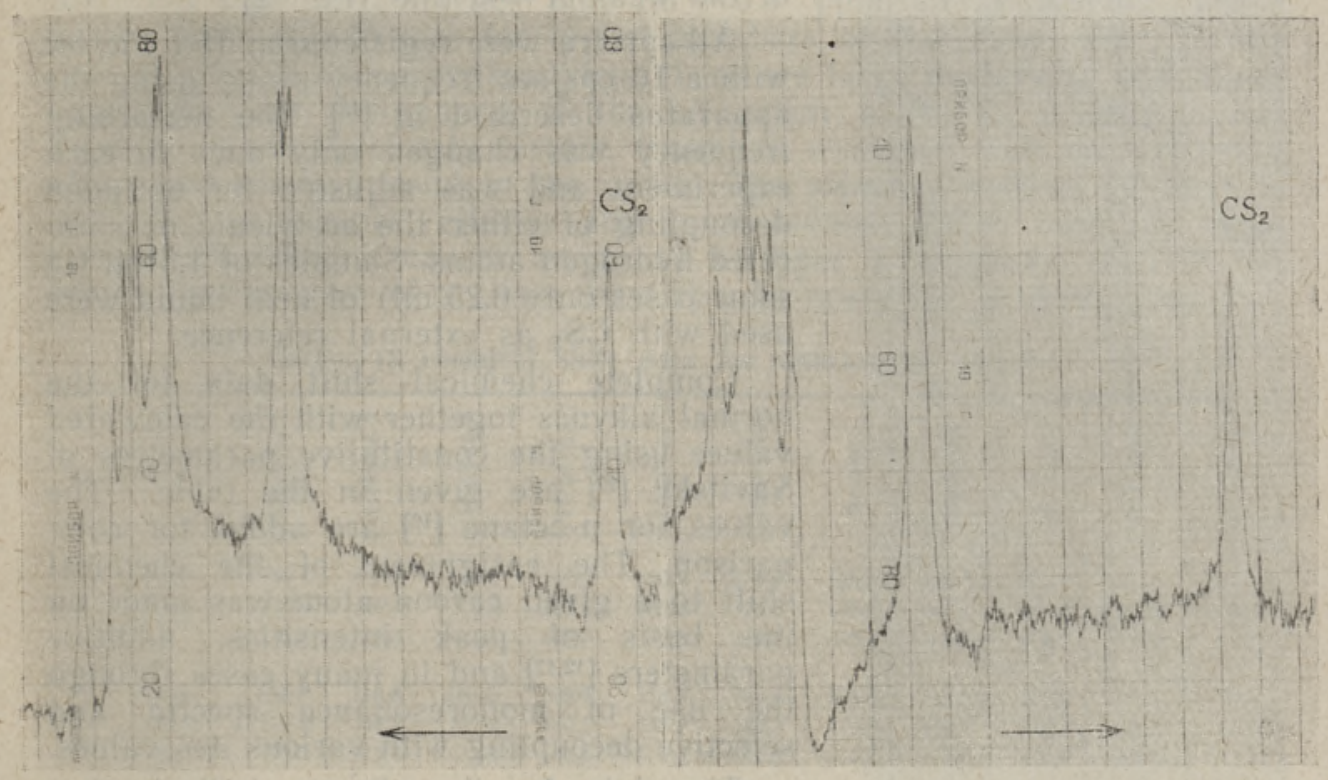

Fig. 1. Fast passage decoupled carbon-13 spectra of octyne-2, registered in two sweep directions.

methylene protons are saturated. For high precision it is advisable to use absorption spectra with not a too strong perturbing rf field [11, $\left.{ }^{13}\right]$, but the sensitivity is much less and the $\pm 0.07 \mathrm{ppm}$ precision is of little use, since acetylenes are particularly susceptible to solvent effects and association. Because of this adiabatic rapid passage $[12,13]$ was used and the mean shift values for both sweep directions calculated. This technique is simple and allows to work much faster with high sensitivity. The precision is less, only $\pm 0.5 \mathrm{ppm}$ and relative line intensities are distorted, but the mean values for both sweep directions are unaffected. Since a very strong $250 \mathrm{mG}$ perturbing $r f$ field with an amplitude of $1080 \mathrm{cps}$ was used, the error caused by the deviation of the perturbing frequency from exact resonance $\Delta \omega_{2}$ is not excessive. If

$$
|\gamma| H_{2} \gg\left|\Delta \omega_{2}\right| ; \quad 2 \pi|J|
$$

then the residual splitting $\left[{ }^{14}, 16\right]$ is $J_{r}=\frac{J \Delta \omega_{2}}{\gamma H_{2}}$. 
Since in normal alkynes $\Delta \delta=1.2 \mathrm{ppm}$ for the saturated part of the molecule [ ${ }^{15}$ ] the residual splitting (about $5 \mathrm{cps}$ ) is much less than the linewidth $1 / \pi T_{2}{ }^{*}$. The $r f$ field strength was

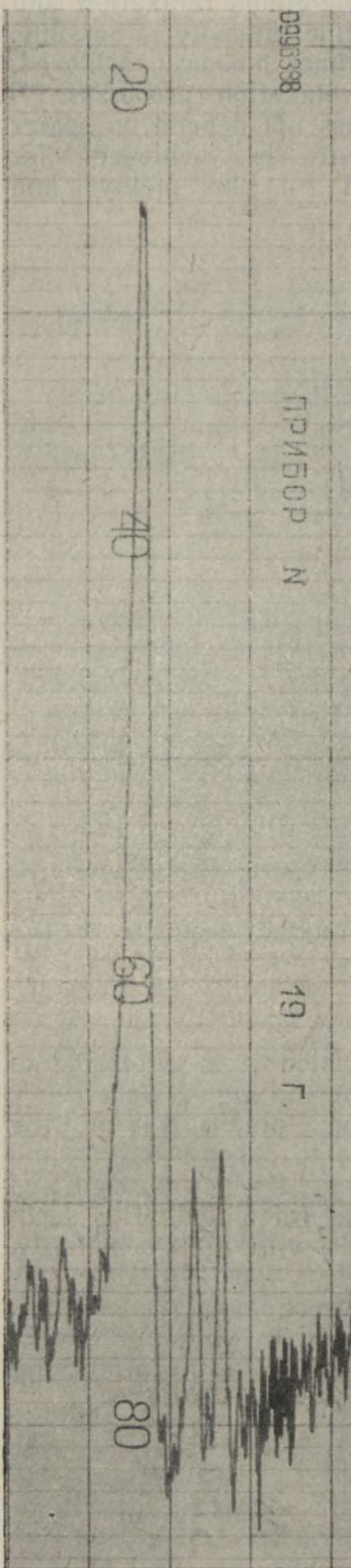
measured from double resonance spectra where the line splitting is in this case nearly equal to the amplitude of one rotating component of the perturbing of field [16]. Although a strong Overhauser effect did not allow any splitting of the $\Lambda=2$ line to be seen, the amplitude $\gamma H_{2} / 2 \pi$ could be approximately measured from the splitting of the weak $A=0$ line (Fig. 2).

All spectra were registered at $15.1 \mathrm{Mc} / \mathrm{sec}$ with a $10 \mathrm{cps} / \mathrm{sec}$ frequency sweep using the apparatus described in [13]. The perturbing frequency was changed only once in each experiment and was adjusted for optimum decoupling of either the acetylenic or saturated hydrogen atoms. Samples of $1.5 \mathrm{ml}$ (in some cases only $0.25 \mathrm{ml}$ ) of neat liquid were used with $\mathrm{CS}_{2}$ as external reference.

Complete chemical shift data for the normal alkynes together with the calculated values using the constitutive parameters of Savitsky $\left[{ }^{17}\right]$ are given in the table. The values for n-octane [12] are added for comparison. The assignment of the chemical shift to a given carbon atom was made on the basis of peak intensities, additive parameters $\left[{ }^{12,17}\right]$ and in many cases through the use of monoresonance spectra and selective decoupling with various $\Delta \omega_{2}$ values.

The data for the alkynes indicate that quite regular trends exist for the chemical shift values. The chemical shifts of carbon atoms in the higher members conform very well with trends established by earlier members of the series where there is no ambiguity in spectral assignment. It is immediately apparent that the triple bond influences only the shifts of immediate neighbours, the $\alpha$-carbon atoms, that show a fairly constant diamagnetic shift about 11 to 13 ppm for both methyl and methylene groups. The possible effect on $\beta$-carbon atoms is certainly less than $1 \mathrm{ppm}$ if it

Fig. 2. Selective double resonance carbon-13. absorption spectrum of benzene. The perturbing $r f$ field was attenuated 17 times from the normal value and centered on one carbon-13 satellite line in the proton spectrum. Unsplit $A=2$ line on the left, the: split $A=0$ line on the right. 
exists at all and the shifts of $\beta, \gamma$ and farther atoms correspond closely to the shifts in similar alkanes. The diamagnetic $11 \mathrm{ppm}$ shift of $\alpha$-methylene carbon atoms relative to atoms in the same position in paraffins is large. As a result of this shift, in some cases the $\alpha$-methylene groups absorb in higher field than the methyl groups of the same molecule. If the shift is caused by magnetic anisotropy of the triple bond $\Delta \chi$, then this anisotropy must be even larger than the highest suggested value $\left.{ }^{18}\right]$. This is inconsistent with the small and paramagnetic $0.1 \mathrm{ppm}$ shift of the $a$-hydrogen atoms in alkynes relative to similar protons in alkenes [15]. The difference of chemical shifts of the two sp-carbon atoms has analytical value. It is $15.2 \pm 0.3 \mathrm{ppm}$ in 1 -alkynes, $3.4 \pm 0.3 \mathrm{ppm}$ in 2-alkynes and $1.6 \pm 0.3 \mathrm{ppm}$ in 3-alkynes. These values have significance for higher members of the series only, in the case of butynes and phenylacetylene there are large deviations from these values $\left[{ }^{3}\right]$. The assignment of the sp-carbon shifts in 3-heptyne and 3 -octyne is not absolutely certain, though it conforms with the inductive effect and general trend in the series. The selective $\gamma$-effect $\left[{ }^{12}\right]$ that is important in alkanes, alkenes and some $o$-disubstituted aromatic compounds $\left.{ }^{20}\right]$ where it causes an up to $2.5 \mathrm{ppm}$ diamagnetic shift of the fourth carbon atom of a chain may also be operative in acetylenes. The

Carbon-13 chemical shift data for unbranched alkynes

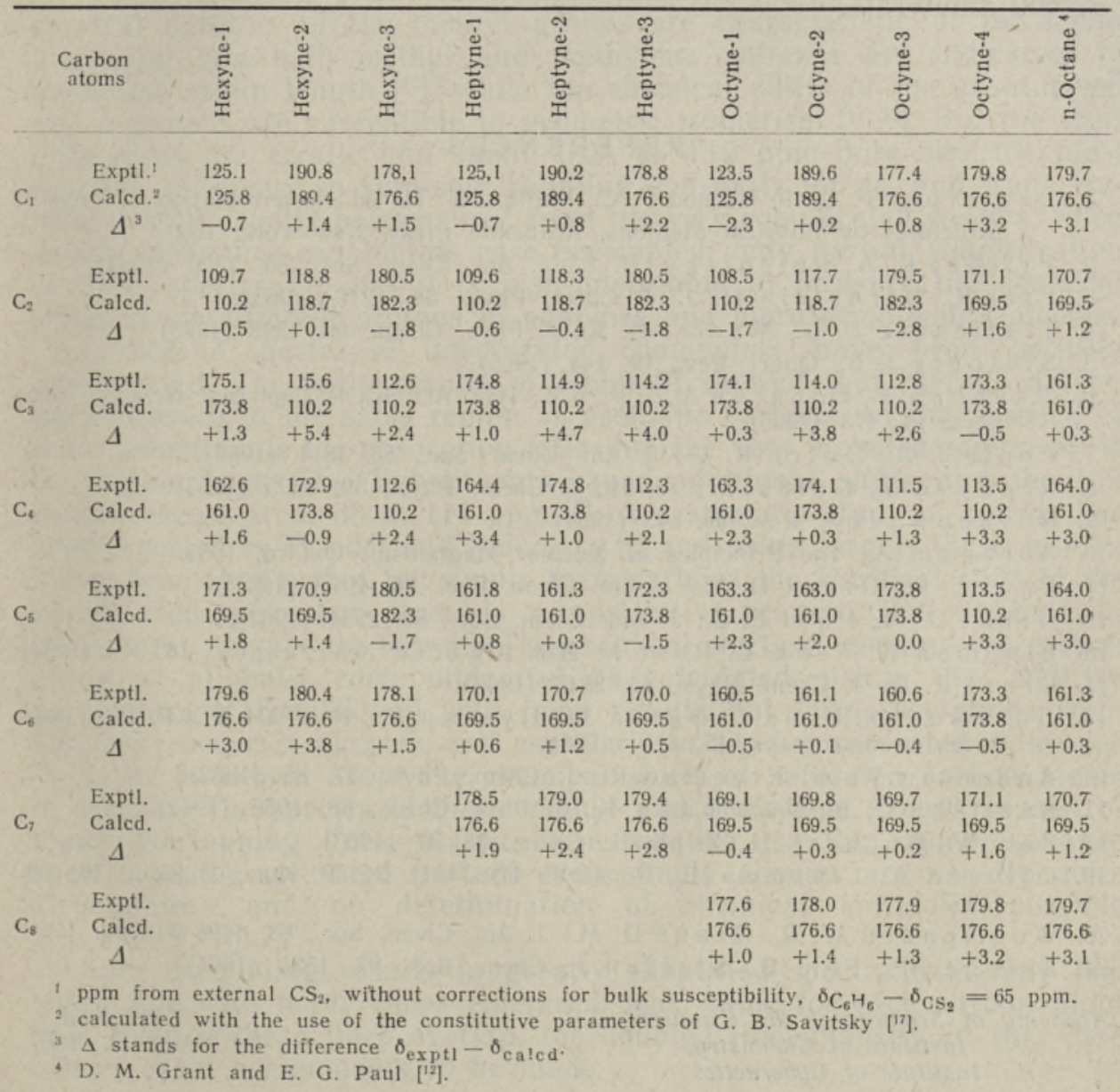


molecular geometry is very different, however, and so the difference in inductive effects of the saturated alkyl groups is considered to be more important in the determination of the chemical shifts of the sp-carbons than such "through space" delocalization effects.

The Overhauser effects provide some insight into the relaxation processes in alkynes. The large increase of line intensity of unsubstituted sp-carbon atoms, even though only more distant hydrogen atoms were saturated, is consistent with the relative insignificance of other relaxation mechanisms for these spins [19], but the very small Overhauser effect of the $\alpha$-methyl group line (Fig. 1) is puzzling since no very effective additional relaxation mechanisms for $\mathrm{sp}^{3}$-carbon atoms are known.

The differences between calculated [17] and measured chemical shifts are small and show that the Savitsky parameters can well be used in the structural analysis of alkynes. One new constant for the $-\mathrm{C} \equiv$ group, $+29 \mathrm{ppm}$ has been added. The equality to the $\equiv \mathrm{C}-$ constant must be purely accidental.

All alkynes were prepared by the usual method of stepwise alkylation of acetylene in liquid ammonia [21] and were purified by fractional distillation through a 40-plate column. The purity was $99.9 \%$ as determined by gas-liquid chromatography with the use of a capillary column of $40 \mathrm{~m}$ in length and $0.2 \mathrm{~mm}$ in diameter coated with triethylene giycol dibutyrate.

\section{REFERENCES}

1. L a uterbur P. C., in Nachod F. C., Phillips W. D., ed,, Determination of Organic Structures by Physical Methods, Academic Press, New York, 1963.

2. Friedel R. A., Retcofsky H. L., J. Am. Chem. Soc., 85, 1300 (1963).

3. Frei K., Bernstein H. J., J. Chem. Phys., 38, 1216 (1963).

4. Traficante D. D., Maciel G. E., J. Phys. Chem., 69, 1348 (1965).

5. St others J. B., Quart. Rev., 19, 144 (1965).

6. Л и п п м а Э., О ли в сон А., П а с т Я., Изв. АН ЭССР. Сер. физ.-матем. и теха. наук, 14, 473 (1965).

7. Pople J. A., Untch K. G., J. Am. Chem. Soc., 88, 4811 (1966).

8. Reddy G. S., Goldstein J. H., J. Chem. Phys., 39, 3509 (1963).

9. Roy de n V., Phys. Rev., 96, 543 (1954).

10. A bragam A., The Principles of Nuclear Magnetism, Oxford, 1961.

11. Pa ul E. G., Grant D. M., J. Am. Chem. Soc., 86, 2977 (1964),

12. Grant D. M., P a u 1 E. G., J. Am. Chem. Soc., 86, 2984 (1964).

13. Lippm a a E., Pehk T., P a st J., Изв. АН ЭССР. Физ., Матем., 16, 345 (1967).

14. Ernst R. R., J. Chem. Phys., 45, 3845 (1966).

15. Липпма а Э., Р анг С., Эйз ен О., Пуск а Р Ю., Изв. АН ЭССР. Сер. физ.матем. и техн. наук, 15,615 (1966).

16. Anderson W. A., Freeman R., J. Chem. Phys., 37, 85 (1962).

17. Savitsky G. B., Namikawa K., J. Phys. Chem., 68, 1956 (1964).

18. Zeil W., Buchert H., Z. physik. Chem., 38, 47 (1963).

19. Olivson A., Lippma a E., Past J., Изв. АН ЭССР. Физ., Матем., 16, 390 (1967).

20. Woolfenden W. R., Grant D. M., J. Am. Chem. Soc., 88, 1496 (1966).

21. Asinger F., Fell B., Steff an J., Chem. Ber., 97, 1555 (1964).

Academy of Sciences of the Estonian SSR,

Institute of Chemistry,

Institute of Cybernetics 